УДК 634

DOI: $10.36718 / 1819-4036-2020-4-80-87$
В.Н. Сорокопудов, С.В. Калугина, Н.С. Кухарук,

М.В. Евтухова, Ю.Ю. Иванова

\title{
СЕЛЕКЦИОННАЯ ОЦЕНКА СОРТОВ КРЫЖОВНИКА НА ПРИГОДНОСТЬ К МЕХАНИЗИРОВАННОЙ УБОРКЕ УРОЖАЯ
}

\author{
V.N. Sorokopudov, S.V. Kalugina, N.S. Kukharuk, \\ M.V. Evtukhova, Yu.Yu. Ivanova
}

\section{SELECTION ASSESSMENT OF GOOSEBERRY VARIETIES FOR SUITABILITY FOR MECHANIZED HARVESTING}

Сорокопудов Владимир Николаевич - д-р с.-х. наук, проф. каф. декоративного садоводства и газоноведения Российского государственного аграрного университета - МСХА им. К.А. Тимирязева, г. Москва. E-mail: sorokopud2301@mail.ru Калугина Светлана Викторовна - канд. биол. наук, доц. каф. природопользования и земельного кадастра Института наук о Земле Белгородского государственного национального исследовательского университета, г. Белгород.

E-mail: Kalugina_S@bsu.edu.ru

Кухарук Наталья Степановна - канд. биол. наук, доц. каф. природопользования и земельного кадастра Института наук о Земле Белгородского государственного национального исследовательского университета, г. Белгород.

E-mail: Kuharuk@bsu.edu.ru

Евтухова Марина Васильевна - канд. биол. наук, начальник управления ландшафтных работ и обслуживания территорий Белгородского государственного национального исследовательского университета, г. Белгород.

E-mail: Evtuhova@bsu.edu.ru

Иванова Юлия Юрьевна - канд. биол. наук, зам. начальника управления ландшафтных работ и обслуживания территорий Белгородского государственного национального исследовательского университета, г. Белгород.

E-mail: Yuivanova@bsu.edu.ru

В начале 70-х годов прошлого века в связи с интенсификацией ягодоводства огромное внимание начали уделять механизированой уборке плодов ягодных культур. О технологии механизированной уборки ягод крыжовника впервые сообщил в 1961 году Christensen. B современных условиях с целью механизированной уборки урожая применяется способ встря-
Sorokopudov Vladimir Nikolaevich - Dr. Agr. Sci., Prof., Chair of Decorative Gardening, Lawn Science, Russian State Agrarian University - K.A. Timiryazev MAA, Moscow. E-mail: sorokopud2301@mail.ru

Kalugina Svetlana Victorovna - Cand. Biol. Sci., Assoc. Prof., Chair of Environmental Management and Land Registry, Institute of Earth Sciences, Belgorod State National Research University, Belgorod. E-mail: Kalugina_S@bsu.edu.ru

Kukharuk Natalya Stepanovna - Cand. Biol. Sci., Assoc. Prof., Chair of Environmental Management and Land Registry, Institute of Earth Sciences, Belgorod State National Research University, Belgorod. E-mail: Kuharuk@bsu.edu.ru

Evtukhova Marina Vasilyevna - Cand. Biol. Sci., Head, Department of Landscape Works and Territories Service, Belgorod State National Research University, Belgorod.

E-mail: Evtuhova@bsu.edu.ru

Ivanova Yulia Yuryevna - Cand. Biol. Sci., Deputy Head, Department of Landscape Works and Territories Service, Belgorod State National Research University, Belgorod.

E-mail:Yuivanova@bsu.edu.ru

хивания. Bопросы и проблемы использования механизированных технологий и средств уборки урожая ягодных культур в нашей стране пока изучены недостаточно. Требование механизированной уборки - высокоурожайные сорта крыжовника с одновременно созревающими ягодами, с кожицей, устойчивой к механическим повреждениям. При этом важно, 
чтобы плоды легко отделялись от плодоножек и чтобы съемные ягоды были сухими. Одно из условий механизированной уборки - это прочное прикрепление листьев к ветвям, так как урожайность ягодных культур будет снижена соразмерно потере листьев при сборе урожая в следующем году. Цель исследований - хозяйственно-биологическая оценка сортов крыжовника на пригодность к механизированной уборке урожая. В результате проведенных исследований на 20 сортообразцах крыжовника, произрастающих в условиях Белгородской области, выявлено, что кусты крыжовника в условиях богарного земледелия в возрасте 6 лет пригодны к механизированной уборке. Особенно выделяются сортообразиы: Черномор, Аладдин, Казачок, Ласковый, Смена. Потенциально пригодными к механизированной уборке урожая выделены сортообразиы: Колобок, Грушенька, Командор, Ласковый, Малахит, Краснославянский, Садко, Финик, Шалун, Сеянец Лефора, Юбилейный. Однако возможно, что при достижении возраста в 7-9 лет отмеченные сорта будут полностью пригодны к уборке урожая комбайновым методом. Полностью непригодными к механизированной уборке урожая выявлены сортообразцы Черный негус (тяжельй/ влажный отрыв ягод; ширина куста у основания на 0,18 м превосходит оnтимальную), Русский (количество урожая в недоступной зоне превышает оптимальные значения на 5-10\%), Прогресс и Славянский (побеги недостаточно эластичны).

Ключевые слова: крьжовник, сорт, габитус кроны, усилие отрыва ягод, усилие раздавливания ягод, пригодность к комбайновой уборке.

In the early 70-s of the previous century, due to the intensification of berry farming, great attention was paid to mechanized harvesting the fruits of berry crops. In 1961Christensen was the first to report about the technology of mechanized harvesting of gooseberries. In modern conditions for the purpose of mechanized harvesting, the method of shaking is used. The issues and problems of using mechanized technologies and means of harvesting berry crops in our country have not yet been studied enough. The requirement for mechanized harvesting is high-yielding varieties of gooseberries with simultaneously maturing berries, with skins resistant to mechanical damage. It is important that the fruits are to be easily separated from the pedicels and that removable berries are to be dry. One of the conditions for mechanized harvesting is a strong attachment of leaves to branches, since the yield of berry crops will be reduced in proportion to the loss of leaves during the harvest next year. The aim of the research is economic and biological assessment of gooseberry varieties for suitability for mechanized harvesting. As a result of studies of 20 gooseberry varieties growing in Belgorod Region, it has been found out that gooseberry bushes at the age of 6 years old are suitable for mechanized harvesting. Varietal specimens are especially suitable: Chernomor, Aladdin, Kazachok, Laskovy, Smena. Varietal samples potentially suitable for mechanized harvesting are: Kolobok, Grushenka, Komandor, Laskovy, Malakhit, Krasnoslavyansky, Sadko, Finik, Shalun, Seyanets Lefora, Yubileiny. However, it is possible that when reaching the age of 7-9 years, the indicated varieties will be fully suitable for harvesting using the combine method. Fully unsuitable varieties of Cherny Negus (heavy/wet separation of berries; bush width at the base by $0.18 \mathrm{~m}$ exceeds the optimal one), Russian (the number of crops in inaccessible zone exceeds the optimal values by 5-10\%), Progress and Slavyansky are completely unsuitable for mechanized harvesting (its shoots are insufficiently elastic).

Keywords: gooseberry, variety, crown habit, berry separation force, berry crushing force, suitability for combine harvesting.

Введение. Уборка плодов ягодных культур может производиться механизированно, что отмечалось многими авторами [1-3]. О технологии механизированной уборки ягод крыжовника впервые сообщалось в 1961 году [4]. В современных условиях с целью механизированной уборки урожая применяется способ встряхивания. Вопросы и проблемы использования механизированных технологий и средств уборки урожая ягодных культур в нашей стране, на наш взгляд, изучены недостаточно. Н.С. Алековым (1975) анализируются технические возможности уборки урожая посредством использования машин ЭЯМ-200-8 и ПАВ-8 [5]. Е.Ю. Ковешниковой (2002) изучен сбор урожая комбайнами типа 
МПЯ-1А, который может быть оценен как более эфрфективный относительно вышеуказанных способов [6]. В.И. Кашин (1995) дает рекомендации по уборке урожая крыжовника с помощью комбайнов МПЯ-1Б, СВК-4С и КПЯ-1 [7].

Требование механизированной уборки - высокоурожайные сорта крыжовника, кроме того, одновременно созревающие ягоды с кожицей, устойчивой к механической обработке [8]. При этом важно, чтобы плоды легко отделялись от плодоножек. Необходимо, чтобы съем ягод был сухим, а также в точке прикрепления плодоножек после уборки оставался рубчик небольшого размера, способный к быстрому высыханию. Одно из условий механизированной уборки это прочное прикрепление листьев к ветвям, так как урожайность ягодных культур будет снижена соразмерно потере листьев при сборе урожая в следующем году [9]. Для повышения качества при применении механизированного способа сбора урожая весьма существенно, чтобы была доступность ягод на кусте. Допустимо не более $15 \%$ урожая в зонах недоступности. По мнению О.Ф. Якименко и В.С. Новопокровского (1988), эфффективность технологий и способов механизированной уборки может быть приемлемой при расположении ягод на расстоянии 0,3-1,8 метров от основания кустов крыжовника [2]. Важное значение имеет синхронность созревания плодов на кусте. Механизированная уборка целесообразна при условии, что более $90 \%$ плодов созревает одновременно [10]. Отмечается влияние габитуса куста крыжовника на вышеуказанные способы уборки урожая. Оптимальный габитус куста будет, когда его форма классифицируется как пряморослая или полураскидистая. Угол наклона между основным количеством крайних ветвей кустов ягодных культур и поверхностью почвы должен варьировать в диапазоне 20-60 градусов.

Наименьшие потери при сборе ягод с помощью механизированных технологий фриксируются при усилии отрыва в диапазоне 50-150 H и усилии раздавливания ягод более $200 \mathrm{H}$. При сборе урожая негативное влияние на товарные свойства может оказывать повреждение плодов колючками и шипами. Следовательно, для наибольшей эфффективности механизированной уборки ягод рекомендуется производителям выращивание сортов крыжовника как слабошиповатых и бесшипных.

Прочность прикрепления плодов к стеблям кустов и предрасположенность ягод к осыпанию определяют полноту сбора урожая ягодных культур. Средние значения этого показателя у Е.Ю. Ковешниковой (2002) определены в размере 168 г, причем отмечается варьирование по различным сортам крыжовника в диапазоне 115-224 г. [6]. Специфика крыжовника проявляется в том, что значение усилия отрыва ягод у данной культуры, даже в случае перезревания плодов, не снижается менее 60 г. Большинство сортов ягод крыжовника могут длительный период времени сохраняться на кустах, при этом могут быть продлены сроки сбора урожая механизированным способом.

Объекты и методы исследований. Объектами изучения послужили 20 сортов крыжовника отечественной и зарубежной селекции. Сорта были посажены по схеме 3х1 м в 3-кратной повторности в условиях Ботанического сада в Белгороде (НИУ БелГУ). В качестве контроля использован сорт крыжовника Русский. Селекционная оценка по пригодности к мехуборке проведена в 2005-2007 годы согласно Программе и методике сортоизучения плодовых, ягодных и орехоплодных культур [11]. Усилие отрыва и раздавливания ягод определяли [12] грамометром в пересчете на Ньютоны $(\mathrm{H})$.

Результаты исследований и их обсуждение. Показатели усилия отрыва в среднем за трехлетний период их изучения варьируют по сортам и изменяются в диапазоне 87-182 Н (Сеянец Лефора, Черный негус) соответственно (табл. 1).

Установлено, что сорт Сеянец Лесрора имел минимальные значения показателей по усилию отрыва ягод. В соответствии со шкалой, разработанной В.Н. Сорокопудовым и Е.В Ереминой (2000), к сортам со слабым усилием отрыва может быть отнесен один сорт из изученных Сеянец Лефора [13].

Для сорта Краснославянский значение усилия раздавливания ягод в среднем за трехлетний период изучения отмечалось от $417 \mathrm{H}$, достигая 693 Н (сорт Грушенька) (табл. 1). 
Сорт Краснославянский демонстрировал усилие раздавливания в $245 \mathrm{H}$, а максимальные показатели в $771 \mathrm{H}$ получены у сорта Ласковый (2005 г.). Минимальные значения усилия раздавливания сорт Краснославянский имел и в 2006, и в 2007 году; они соответственно составили 500 и $507 \mathrm{H}$. Наибольшее усилие раздавливания у сорта Юбилейный - 693 Н (2006 г.) и у сорта Грушенька - 695 Н (2007 г.). Все изученные сорта показали значения по усилию раздавливания выше $200 \mathrm{H}$, что характеризует их пригодность к комбайновому методу уборки урожая (табл. 2). Форма кустов была практически постоянной, по сортам изменялась от компактной до полураскидистой. Сорта крыжовника вышеуказанной фрормы кустов рекомендуются в качестве приемлемых для механизированного способа сбора урожая. Для повышения эффрективности механизированного метода съема ягод, у которых оптимальная ширина куста у основания составляет 0,3 м, высота куста должна ставлять 1,0-1,2 м [6].

Ширина основания куста всех изученных сортов крыжовника не выходила за рамки оптимального уровня в 2005 году. Данная величина в среднем была 0,18 м и изменялась от 0,1 м (сорт Славянский) до 0,23 м (сорта Финик и Колобок). Средние аналогичные параметры в 2006 году составили 0,24 м, варьируя в соответствии с сортом: Славянский, Шалун - от 0,16-0,17 м; Колобок, Черный негус, Леденец - до 0,3 м. Данные таблицы 2 показывают, что ширина основания куста существенно превышает оптимальное значение, составляя у сорта Черный негус 0,48 м (2007 г.).

В период экспериментальных исследований возраст посадок крыжовника составлял от четырех до шести лет. В соответствии с чем кусты крыжовника не достигли своих максимальных показателей развития, следовательно, высота растений на период окончания эксперимента большинства сортов не будет оптимальной, требуемой для эффрективного механизированного способа уборки ягод.

В конце эксперимента сорта Ласковый, Аладдин, Смена, Черный негус, Черномор, Казачок были по высоте куста от 0,95 до 1,25 м.
Средняя высота других изученных сортов изменялась от 0,5 до 0,85 м.

В соответствии с анализом показателей по количеству урожая, локализующегося в недоступной зоне, представленных в таблице 2, установлено, что девятнадцать сортов из двадцати оцениваются нами как целесообразные и эффективные для механизированной уборки ягод. Однако данные сорта показывают наличие от 2 до 12 \% урожая ягод крыжовника в недоступной зоне. При этом сорт Русский имеет максимальные значения от 20 до $25 \%$.

Основные свойства сортов, обосновывающие их пригодность к механизированным технологиям сбора урожая ягод крыжовника, приведены в таблице 3. На основе анализа показателя одновременности созревания плодов по сортам установлена следующая закономерность: у всех сортов отмечено практически одновременное созревание - более 90 \% плодов.

Существенным критерием при верификации сорта на пригодность к механизированному способу уборки следует признать качество отрыва плода от плодоножки. Оптимальными по пригодности будут сорта, у которых усилие отрыва легкое и среднее. Важно, чтобы в данном случае не была нарушена целостность ягоды в месте отрыва. С соответствии с оценкой, проведенной в ходе экспериментальных работ, могут быть рекомендованы к использованию все изученные сорта крыжовника, кроме сорта Черный негус. У данного сорта отрыв ягоды классифицируется как тяжелый и влажный.

Побеги являются достаточно прочными и эластичными у 18 сортов, что имеет определяющее значение при уборе урожая с помощью механизированных средств. Недостаточную эластичность ветвей для уборки плодов комбайнами показали только сорта Славянский и Прогресс.

Шиповатость побегов крыжовника - важный критерий при выявлении пригодности сорта к механизированной технологии сбора плодов крыжовника. Выявлено, что все представленные сорта пригодны для механизированной уборки. 


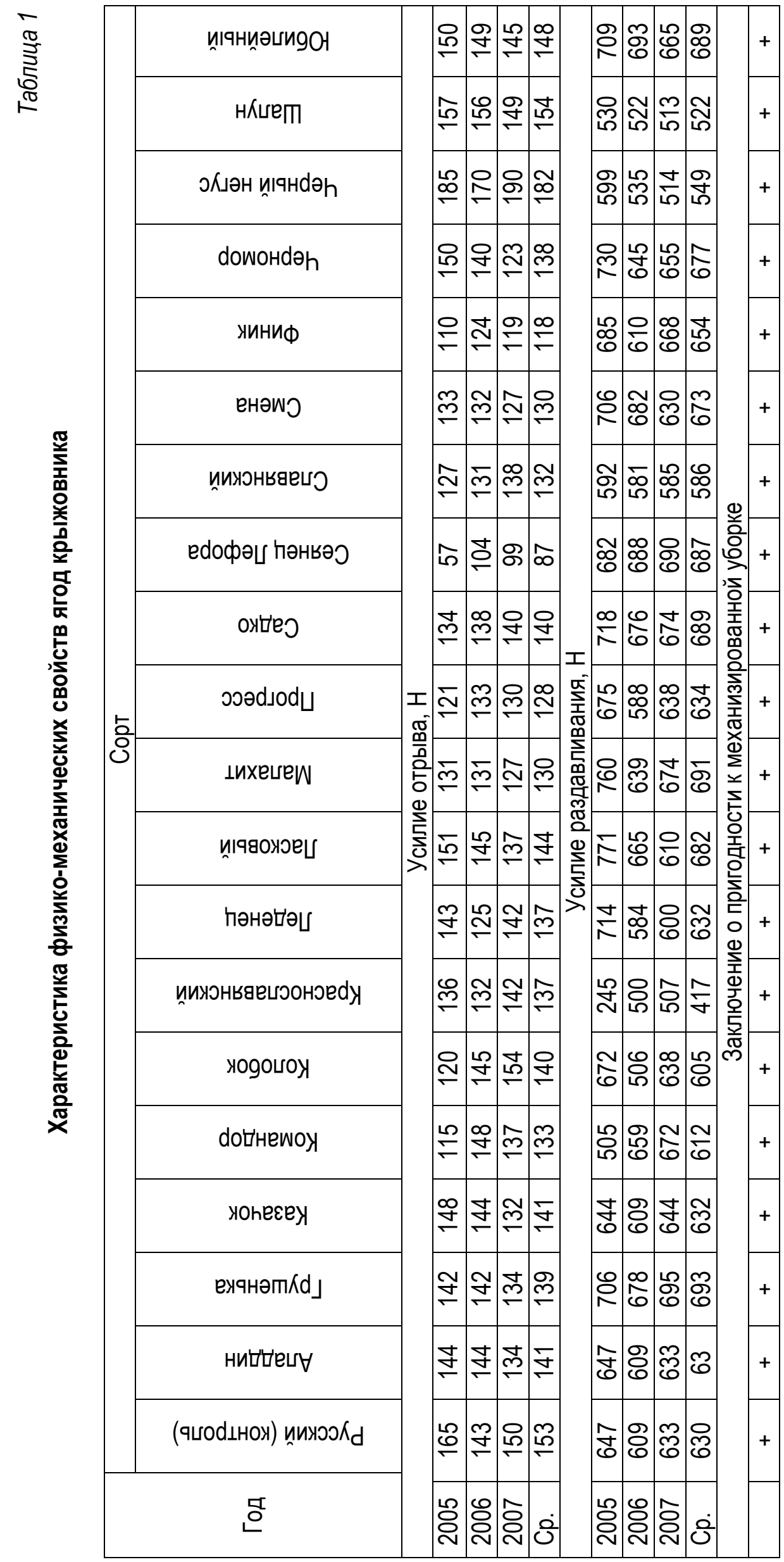




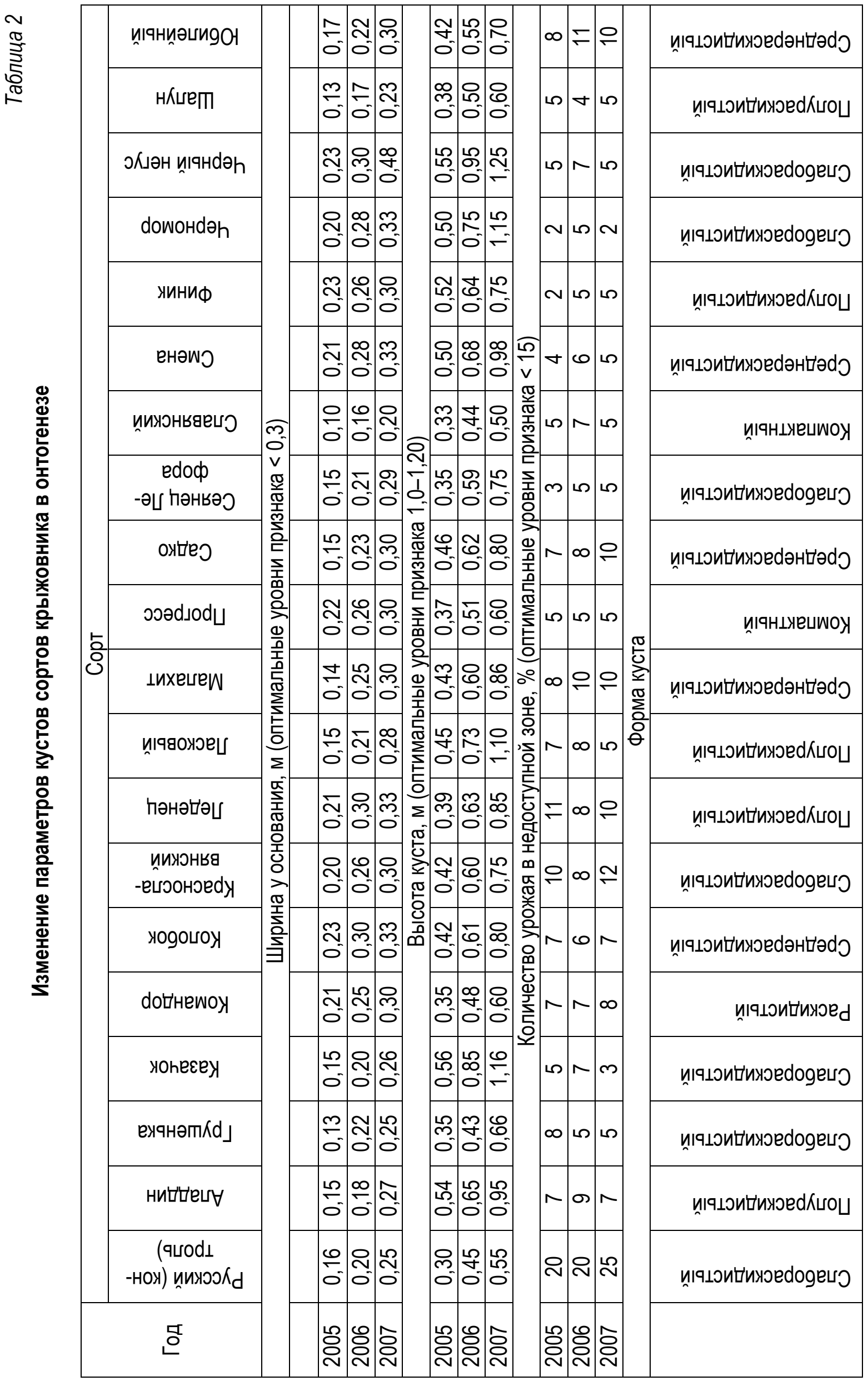




\section{Пригодность сортов крыжовника к механизированным технологиям сбора урожая по лимитирующим признакам}

\begin{tabular}{|c|c|c|c|c|c|c|c|}
\hline $\begin{array}{l}\text { Сортообра- } \\
\text { зец }\end{array}$ & $\begin{array}{c}\text { Количество } \\
\text { урожая в } \\
\text { недоступ- } \\
\text { ных зонах }\end{array}$ & $\begin{array}{l}\text { Одновре- } \\
\text { менное } \\
\text { созрева- } \\
\text { ние }\end{array}$ & $\begin{array}{l}\text { Усилие } \\
\text { отрыва }\end{array}$ & $\begin{array}{l}\text { Усилие } \\
\text { раздав- } \\
\text { ливания }\end{array}$ & Отрыв & $\begin{array}{c}\text { Эластич- } \\
\text { ность вет- } \\
\text { вей }\end{array}$ & $\begin{array}{c}\text { Пригод- } \\
\text { ность сорта }\end{array}$ \\
\hline $\begin{array}{l}\text { Oптималь- } \\
\text { ные уровни } \\
\text { признака }\end{array}$ & $<15 \%$ & $\begin{array}{c}>90 \% \text { в } \\
\text { один срок }\end{array}$ & $\begin{array}{c}50-150 \\
H\end{array}$ & $>200 \mathrm{H}$ & $\begin{array}{c}\text { Легкий- } \\
\text { сред- } \\
\text { ний/сухой }\end{array}$ & Эластичные & +++++ \\
\hline $\begin{array}{l}\text { Русский } \\
\text { (контроль) }\end{array}$ & 22 & $90-95$ & 180 & 682 & Легкий/сухой & Эластичные & -+++++ \\
\hline Аладдин & 8 & $95-100$ & 141 & 630 & Сред/сухой & Эластичные & ++++++ \\
\hline Грушенька & 6 & $95-100$ & 139 & 693 & Сред/сухой & Эластичные & ++++++ \\
\hline Казачок & 5 & $90-100$ & 141 & 632 & Легкий/сухой & Эластичные & ++++++ \\
\hline Командор & 7 & 95-100 & 133 & 612 & Сред/сухой & Эластичные & +++++++ \\
\hline Колобок & 7 & $95-100$ & 140 & 605 & Сред/сухой & Эластичные & +++++++ \\
\hline $\begin{array}{l}\text { Красносла- } \\
\text { вянский. }\end{array}$ & 10 & 95-100 & 137 & 417 & Сред/сухой & Эластичные & ++++++ \\
\hline Леденец & 10 & $90-95$ & 144 & 695 & Сред/сухой & Эластичные & ++++++ \\
\hline Ласковый & 7 & $95-100$ & 137 & 632 & Сред/сухой & Эластичные & ++++++ \\
\hline Малахит & 9 & 90-95 & 130 & 695 & Сред/сухой & Эластичные & +++++++ \\
\hline Прогресс & 5 & $85-90$ & 128 & 634 & Сред/сухой & Эластичные & +++++- \\
\hline Садко & 8 & $95-100$ & 140 & 689 & Сред/сухой & Эластичные & +++++ \\
\hline $\begin{array}{l}\text { Сеянец } \\
\text { Лефора }\end{array}$ & 4 & 90-95 & 87 & 693 & Сред/сухой & Эластичные & ++++++ \\
\hline Славянский & 6 & $90-95$ & 132 & 586 & Сред/сухой & Эластичные & +++++- \\
\hline Смена & 3 & $95-100$ & 130 & 673 & Сред/сухой & Эластичные & ++++++ \\
\hline Финик & 4 & $90-95$ & 118 & 654 & Сред/сухой & Эластичные & +++++++ \\
\hline Черномор & 3 & $90-95$ & 138 & 677 & Сред/сухой & Эластичные & ++++++ \\
\hline $\begin{array}{l}\text { Черный } \\
\text { негус }\end{array}$ & 6 & $90-95$ & 139 & 549 & Тяжел/влаж & Эластичные & +++++- \\
\hline Шалун & 5 & $90-100$ & 154 & 522 & Сред/сухой & Эластичные & +++++++ \\
\hline Юбилейный & 10 & $95-100$ & 148 & 689 & Сред/сухой & Эластичные & +++++++ \\
\hline
\end{tabular}

\section{Выводы}

1. В результате проведенных исследований 20 сортов крыжовника в условиях богарного земледелия юго-запада ЦЧЗ выявлено, что сорта крыжовника в возрасте 6 лет пригодны к механизированной уборке.

2. Наиболее пригодными выделены сорта: Черномор, Аладдин, Казачок, Ласковый, Смена. Потенциально-пригодными к механизированной уборке урожая выделены сортообразцы: Колобок, Грушенька, Командор, Ласковый, Малахит, Краснославянский, Садко, Финик, Шалун, Сеянец Лефора, Юбилейный.

3. Полностью непригодным к механизированной уборке урожая выявлен сорт Черный негус, имеющий тяжелый отрыв ягод, с шириной куста у основания, превосходящей оптимальную на 0,18 м. Сорт Русский не пригоден к механи- зированной уборке ввиду превышения у него оптимального значения урожая в недоступной зоне на 5-10\%. У сортов Прогресс и Славянский выявлены недостаточно эластичные побеги, поэтому урожай не может быть убран механизированным способом.

\section{Литература}

1. Белосохов Ф.Г. Хозяйственно-биологическая оценка сортообразцов жимолости в Тамбовской области: автореср. дис. ... канд. с.-Х. наук. Мичуринск, 1993. 22 с.

2. Якименко О.Ф., Новопокровский В.С. Оценка и подбор черной смородины для машинной уборки урожая: метод. рекомендации / ВНИИС им. И.В. Мичурина. Мичуринск, 1988. 18 с.

3. Еремина Е.В. Селекционное изучение исходного материала крыжовника для создания сортов в условиях лесостепи Приобья: авто- 
реф. дис. ... канд. с.-х. наук. Новосибирск, 2003. $16 \mathrm{c}$.

4. Christensen J.V. Mechanical harvesting of berries. Prospects and problems // Proc. Balsgard Fruit Brdg Symp., Fjälkestad 1964. 1966. P. 90 92.

5. Алеков Н.С. Механизация уборки урожая крыжовника // Сб. науч. работ ВНИИС им. И.В. Мичурина. Мичуринск, 1975. Вып. 21. C. 235-239.

6. Ковешникова Е.Ю. Хозяйственнобиологическая оценка сортов крыжовника в условиях средней полосы РФ: автореф. дис. ... канд. С.-х. наук. Мичуринск, 2002. 27 с.

7. Кашин В.И. Научные основы адаптивного садоводства. М.: Колос, 1995. 335 с.

8. Сорокопудов В.Н., Мелькумова Е.А., Сорокопудова О.А. Крыжовник в Сибири. Новосибирск: Новосиб. кн. изд-во, 1999. 92 с.

9. Kun Э. Смородина и крыжовник // Селекция плодовых растений. М.: Колос, 1981. С. 274371.

10. Нигматзянов Р.А., Сорокопудов В.Н. Перспективы селекции смородины черной по качеству ягод в условиях Башкирского Предуралья // Вестник КрасГАУ. 2020. № 1. С. 3439. DOI:10.36718/1819-4036-2020-1-34-39.

11. Князев С.Д., Баянова Л.В. Смородина, крыжовник и их гибриды // Программа и методика сортоизучения плодовых, ягодных и орехоплодных культур. Орел: ВНИИСПК, 1999. C. 351-373.

12. Утков Ю.А., Якименко Ю.Ф., Гурин А.Г. Изучение пригодности сортов к машинной уборке урожая // Программа и методика сортоизучения плодовых, ягодных и орехоплодных культур. Орел: ВНИИСПК, 1999. С. 184-186.

13. Сорокопудов B.Н., Еремина Е.В. Оценка сортов и гибридов крыжовника на пригодность к механизированной уборке урожая // Сибирская аграрная наука III тысячелетия: тез. докл. конф. молодых ученых СО РАСХН (26 апреля 2000 г., Краснообск). Новосибирск, 2000a. - C. 81.

\section{Literatura}

1. Belosohov F.G. Hozjajstvenno-biologicheskaja ocenka sortoobrazcov zhimolosti v Tam-bovskoj oblasti: avtoref. dis. ... kand. s.-h. nauk. Michurinsk, 1993. $22 \mathrm{~s}$.

2. Jakimenko O.F., Novopokrovskij V.S. Ocenka i podbor chernoj smorodiny dlja mashinnoj uborki urozhaja: metod. rekomendacii / VNIIS im. I.V. Michurina. Michurinsk, 1988. $18 \mathrm{~s}$.

3. Eremina E.V. Selekcionnoe izuchenie ishodnogo materiala kryzhovnika dlja sozdanija sortov v uslovijah lesostepi Priob'ja: avtoref. dis. ... kand. s.-h. nauk. Novosibirsk, 2003. 16 s.

4. Christensen J.V. Mechanical harvesting of berries. Prospects and problems // Proc. Balsgard Fruit Brdg Symp., Fjälkestad 1964. 1966. P. 90 92.

5. Alekov N.S. Mehanizacija uborki urozhaja kryzhovnika // Sb. nauch. rabot VNIIS im. I.V. Michurina. Michurinsk, 1975. Vyp. 21. S. 235239.

6. Koveshnikova E.Ju. Hozjajstvennobiologicheskaja ocenka sortov kryzhovnika $\mathrm{v}$ uslo-vijah srednej polosy RF: avtoref. dis. ... kand. s.-h. nauk. Michurinsk, 2002. 27 s.

7. Kashin V.I. Nauchnye osnovy adaptivnogo sadovodstva. M.: Kolos, 1995. $335 \mathrm{~s}$.

8. Sorokopudov V.N., Mel'kumova E.A., Sorokopudova O.A. Kryzhovnik v Sibiri. Novosibirsk: Novosib. kn. izd-vo, 1999. $92 \mathrm{~s}$.

9. Kip Je. Smorodina i kryzhovnik // Selekcija plodovyh rastenij. M.: Kolos, 1981. S. 274-371.

10. Nigmatzjanov R.A., Sorokopudov V.N. Perspektivy selekcii smorodiny chernoj po kachestvu jagod v uslovijah Bashkirskogo Predural'ja // Vestnik KrasGAU. 2020. № 1. S. 34-39. DOI: 10.36718/1819-4036-2020-1-34-39.

11. Knjazev S.D., Bajanova L.V. Smorodina, kryzhovnik i ih gibridy // Programma i meto-dika sortoizuchenija plodovyh, jagodnyh i orehoplodnyh kul'tur. Orel: VNIISPK, 1999. S. 351-373.

12. Utkov Ju.A., Jakimenko Ju.F., Gurin A.G. Izuchenie prigodnosti sortov $\mathrm{k}$ mashinnoj uborke urozhaja // Programma i metodika sortoizuchenija plodovyh, jagodnyh i oreho-plodnyh kul'tur. Orel: VNIISPK, 1999. S. 184-186.

13. Sorokopudov V.N., Eremina E.V. Ocenka sortov i gibridov kryzhovnika na prigodnost' k mehanizirovannoj uborke urozhaja // Sibirskaja agrarnaja nauka III tysjacheletija: tez. dokl. konf. molodyh uchenyh SO RASHN (26 aprelja 2000 g., Krasnoobsk). Novosibirsk, 2000a. S. 81. 